\title{
Acute and chronic haemodynamic and electrophysiological effects of nifedipine in patients receiving atenolol
}

\author{
E ROWLAND, P RAZIS, ^ D SUGRUE, D M KRIKLER \\ From the Division of Cardiovascular Disease, Royal Postgraduate Medical School, London
}

SUMMARY The action of nifedipine given first intravenously and then orally was studied in nine patients undergoing investigation for angina pectoris who were already receiving atenolol (100-200 $\mathrm{mg} /$ daily) and who had been shown to be fully beta blocked (reduction in maximal heart rate by $>25 \%$ ). Intravenous nifedipine $7.5 \mu \mathrm{g} / \mathrm{kg}$ reduced both systolic blood pressure and left ventricular pressure $(\mathrm{dP} / \mathrm{dt}$ ) transiently; both values were significantly lower five and 10 minutes after the infusion of nifedipine but were not significantly different from control values at 20 minutes. There was minimal but pronounced depression of atrioventricular nodal function after giving intravenous nifedipine, though this was detected only when sensitive tests of atrioventricular nodal function were used. These effects were also transient, showing no significant change from control values at 20 minutes. Atrioventricular nodal conduction time and sinus rate were unchanged. Radionuclide angiography of patients taking the oral combination of atenolol and nifedipine for chronic angina showed no change in ejection fraction compared with those taking atenolol alone, but there was a small increase in peak ejection rate. Resting blood pressure and heart rate were unchanged and the PR interval did not lengthen. Peak heart rate and systolic blood pressure showed no alteration on exercise testing when the drugs were combined compared with the response with atenolol alone.

Despite the negative inotropic influence when nifedipine was given intravenously, the absence of haemodynamic deterioration when oral nifedipine is combined with atenolol has confirmed that this combination can be used safely in patients with normal left ventricular function. The minimal changes in atrioventricular nodal function cannot be detected on the surface electrocardiogram and are not of clinical importance in patients with normal conduction.

Beta adrenoceptor blocking drugs are used extensively in the treatment of angina pectoris and hypertension. Their efficacy is not, however, uniform and their use often limited by side effects when given in maximal doses. ${ }^{1}$ More recently, the calcium antagonists have been shown to possess a variety of cardiovascular actions which are also of value in the treatment of these diseases. ${ }^{2}$ Although these two groups of compounds have similar indications, their modes of action are quite different. The calcium antagonists influence the ionic currents that are associated with the electrical activity of ventricular myocardium, parts of the specialised conducting system, and vascular smooth

^Present address: Department of Anaesthetics, Whittington Hospital, London N6.

Accepted for publication 21 June 1983 muscle. ${ }^{34}$ It has been recognised, however, that there are important differences between the various members of the group which appear to reflect different cellular mechanisms of action. ${ }^{56}$ While verapamil and diltiazem have both electrophysiological and vasoactive effects, nifedipine is selective for vascular smooth muscle. ${ }^{78}$ Nifedipine has been shown to be of value in the treatment of angina9-11 especially when combined with beta adrenoceptor blocking drugs. ${ }^{12-14}$

The differing properties of beta blockers on the one hand and calcium antagonists on the other have been combined to advantage in the treatment of angina pectoris. Two aspects of their combination have, however, given cause for concern. Isolated cases of haemodynamic deterioration have been reported using the combination of beta blockers with both nifedipine ${ }^{15-17}$ and verapamil. ${ }^{18-22}$ Formal studies of 
the haemodynamic effects of nifedipine in combination with atenolol, acebutolol, metoprolol, and propranolol have, however, shown no deterioration with acute or short term administration, even in patients with moderately depressed left ventricular function. 22-26 There has not, however, been a long term evaluation of using beta blockade alone against atenolol and nifedipine in combination, nor has the effect of nifedipine been observed in patients who are shown to be uniformly beta blocked. The second aspect of concern centres on the possibility of an electrophysiological interaction. Asystole has occurred when intravenous verapamil was given in the presence of chronic beta blockade. ${ }^{27}$ Further prolongation of atrioventricular nodal conduction is seen when oral verapamil is added to propranolol..$^{22}$ Nifedipine, by contrast, produced no change when combined with propranolol $^{22}$ and lacked the depressant electrophysiological properties of verapamil when used alone in clinical doses. ${ }^{28} 29$ Electrophysiological impairment of atrioventricular nodal conduction with nifedipine can be shown experimentally when sufficient doses are used, and the sensitivity to these effects is enhanced when sympathetic innervation is removed. ${ }^{30}$

This study was undertaken to provide a systematic evaluation of the electrophysiological and haemodynamic interaction between nifedipine, given both acutely and chronically, and atenolol given in full beta blocking doses.

\section{Patients and methods}

Nine patients were recruited for the study before undergoing routine cardiac catheterisation for the investigation of exertional chest pain. Informed consent was obtained. Patients with clinical signs of heart failure, atrioventricular block, obstructive airways disease, or recent ( $<6$ months) myocardial infarction were excluded from the study. The ability to exercise adequately was established beforehand and only those patients who had ejection fractions of $\geqslant 0.40$ on both radionuclide and contrast angiography were included. Control recordings were made only after all cardioactive medications with the exception of glyceryl trinitrate had been discontinued for at least five times the half life.

\section{PROTOCOL}

The control recordings comprised supine and erect heart rate and blood pressure, exercise testing, and multigated radionuclide angiography. Supine heart rate and blood pressure were recorded after 10 minutes recumbency and the erect values after the patient had stood for two minutes. Maximal exercise testing on an electronically braked bicycle ergometer
(Siemen-Elema) was performed to the point of fatigue, tiredness, shortness of breath, or angina. The protocol incorporated stepwise increments of $25 \mathrm{~W}$, starting at $50 \mathrm{~W}$, and maintaining the pedal rate at 50 rpm. The load was increased every minute and subsequent exercise tests followed the same regimen. The heart rate and systolic blood pressure were recorded for each minute during and for 10 minutes after peak exercise. Where the duration of exercise was limited by beta blockade peak blood pressure and heart rate measurements were compared at the same point of exercise with each treatment. Left ventricular function was assessed non-invasively by technetium-99m multigated radionuclide angiography. Red blood cells were labelled in vivo using $15 \mathrm{mCi}$ technetium-99m as pertechnetate and then equilibrium blood pool images were acquired in frame mode using a gamma camera with a large field of view (GE Maxi 400T). Ejection fraction (\%) and peak ejection rate, expressed as change in end diastolic volumes per second (edv/s), were calculated according to our usual method. ${ }^{31}$

Atenolol $100 \mathrm{mg} /$ day was then given for 10 days at which point the exercise test was repeated. Adequate beta blockade was confirmed by a reduction in maximum heart rate of $>25 \%$; in three patients it was necessary to increase the atenolol to $200 \mathrm{mg}$ /day for a further three days to achieve this criterion. Patients were then admitted to hospital for routine cardiac catheterisation on the fourteenth day of treatment with atenolol. Within six hours before catheterisation radionuclide angiography was performed, as was measurement of supine and erect heart rate and blood pressure and exercise testing, in the three patients requiring the higher dose of atenolol.

After contrast angiography a catheter tip transducer advanced through a $120 \mathrm{~cm}$ introducing sheath recorded left ventricular pressure continuously: the sheath was withdrawn from the left ventricle and positioned in the ascending aorta to allow the continuous display of aortic blood pressure. The left ventricular pressure trace was recorded and also fed to a differential amplifier (Electronics for Medicine) to provide the peak positive first derivative $(\mathrm{dP} / \mathrm{dt})$ averaged over 25 cardiac cycles to compensate for respiratory variability. Technical difficulties in positioning the catheter tip transducer and associated ventricular irritability prevented the recording of left ventricular pressure in one patient. Two electrode wires were introduced via the right femoral vein and advanced to the right atrium and adjacent to the bundle of His. Heart rate and intracardiac conduction intervals (PA, AH, and $\mathrm{HV}$ intervals) were recorded continuously. In addition to the continuous recording of atrioventricular nodal conduction time (AH interval) two other methods of assessing atrioventricular nodal function were used. Firstly, the effective refrac- 
tory period was measured at two basic atrial pacing rates ( 80 and 100 beats/minute). In one patient atrial refractoriness was longer than that of the atrioventricular node and a value could not be obtained. Secondly, continuous incremental atrial pacing was performed until second degree atrioventricular nodal block occurred and this interval was recorded as the Wenckebach cycle length. One patient developed chest discomfort and could not be re-evaluated at 20 minutes. Pacing was performed at twice diastolic threshold using rectangular stimuli of $2 \mathrm{~ms}$ duration generated from a programmable stimulator (Bloom Associates Ltd, Narberth, Pennsylvania, USA).

Nifedipine was drawn up under sodium light into a light proof syringe and delivered into a peripheral vein via a light shielded cannula. After measurement of baseline haemodynamic and electrophysiological variables nifedipine $7.5 \mu \mathrm{g} / \mathrm{kg}$ was given intravenously over five minutes. Electrophysiological reassessment of atrioventricular nodal function was performed between five and 10 minutes and again between 15 and 20 minutes after the end of the infusion. On the day after catheterisation nifedipine $30 \mathrm{mg} /$ day was given orally in addition to the atenolol, and after three days was increased to $60 \mathrm{mg} /$ day. On the tenth day the patients were re-evaluated with exercise testing, measurement of erect and supine heart rate and blood pressure, and radionuclide angiography.

Changes in the variables were analysed statistically by Student's $t$ test for paired samples.

\section{Results}

Coronary arteriography showed that five patients had two vessel disease (defined as stenosis $>70 \%$ ), two had single vessel disease, and two were normal: in all


Fig. 1 Changes in left ventricular systolic pressure, left ventricular end diastolic pressure, and peak positive dP/dt after intravenous nifedipine ( $7.5 \mu \mathrm{g} / \mathrm{kg}$ over five minutes) in eight patients receiving atenolol. Bars represent means ( $\pm S E M)$ for control $(C)$ and at 10 and 20 minutes after the infusion.
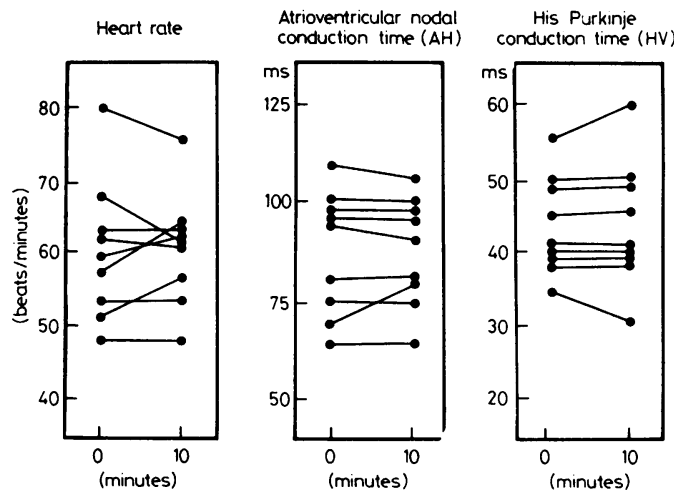

Fig. 2 Heart rate, atrioventricular nodal conduction time (AH interval), and His-Purkinje conduction time (HV interval) before $(O)$ and 10 minutes after intravenous nifedipine. Results are means $\pm S E M$.

cases the left ventricular end diastolic pressure was normal ( $\leqslant 18 \mathrm{mmHg}$ ).

\section{EVALUATION OF INTRAVENOUS NIFEDIPINE}

Nifedipine produced a brief but significant fall in the left ventricular systolic blood pressure and peak positive $\mathrm{dP} / \mathrm{dt}$ in the eight patients in whom it was recorded. The systolic pressure fell from a control value (mean $\pm S E M$ ) of $117 \pm 6 \mathrm{mmHg}$ to $110 \pm 5$ $\mathrm{mmHg}(\mathrm{p}<0.05) 10$ minutes after the infusion (Fig. 1). The reduction in mean systolic pressure at 20 minutes $(113 \pm 6 \mathrm{mmHg}$ ) was, however, no longer statistically significant. The changes in left ventricular peak $\mathrm{dP} / \mathrm{dt}$ followed a similar pattern: at 10 minutes the control value $(1366 \pm 101 \mathrm{mmHg} / \mathrm{s})$ had been reduced to $1267 \pm 88 \mathrm{mmHg} / \mathrm{s}(\mathrm{p}<0.05)$ but had
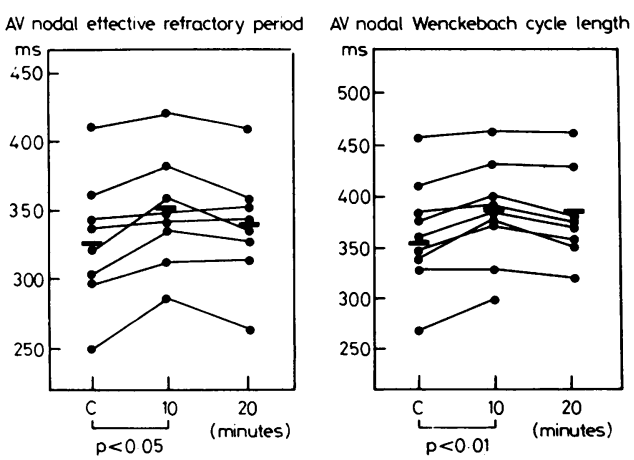

Fig. 3 Effect of intravenous nifedipine on atrioventricular nodal effective refractory period and Wenckebach cycle length. Results for each patient are shown before $(C)$ and after (10 and 20 minutes) the drug, as is the mean (-) for each group of recordings. 

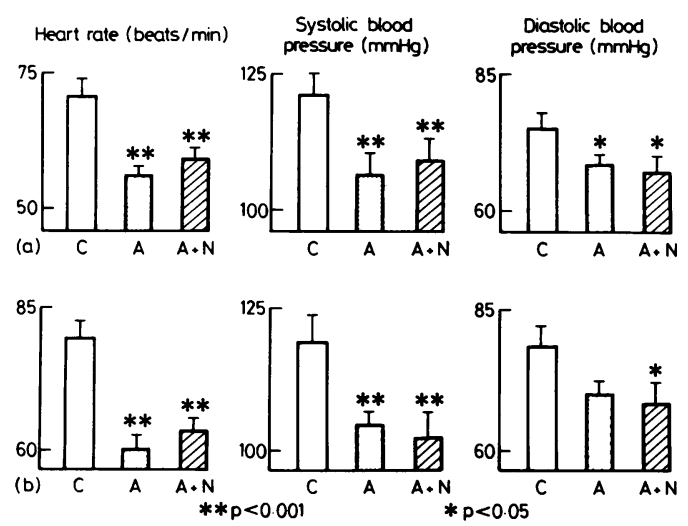

Fig. 4 Changes in (a) supine and (b) erect heart rate and blood pressure with atenolol $(A)$ and with the combination of atenolol and nifedipine $(A+N)$ compared with control $(C)$. Bars represent means $\pm S D$.

returned to $1302 \pm 86 \mathrm{mmHg} / \mathrm{s}(p>0.05)$ by 20 minutes. The left ventricular end diastolic pressure remained unchanged throughout.

There were no significant changes in sinus rate or atrioventricular nodal or His-Purkinje conduction times (Fig. 2). There were significant increases in both the effective refractory period (control, $327 \pm 17$ ms; nifedipine, $345 \pm 15 \mathrm{~ms}$ (mean \pm SEM) $\mathrm{p}<0.05$ ) and the Wenckebach cycle length of the atrioventricular node (control, $363 \pm 18 \mathrm{~ms}$; nifedipine, $381 \pm 17$ ms; $\mathrm{p}<0.01$ ) at five to 10 minutes (Fig. 3). Significance was lost when these values were reassessed at 15 to 20 minutes.

\section{EVALUATION OF THE ORAL COMBINATION}

There was a minimal increase in resting mean heart rate in both supine and erect positions when
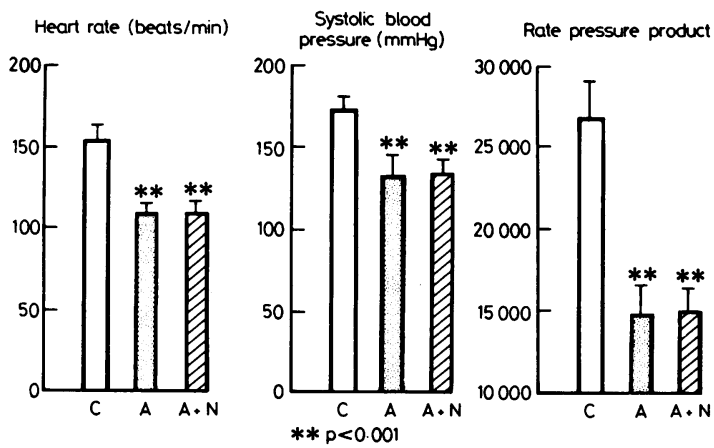

Fig. 5 Effects of atenolol $(A)$ and atenolol combined with nifedipine $(A+N)$ on heart rate, systolic blood pressure, and rate pressure product at peak exercise compared with control $(C)$. Bars represent means $\pm S E M$.


Fig. 6 Changes in ejection fraction (\%) and peak ejection rate (edv/s) as assessed by $99 \mathrm{~m} \mathrm{~T}$ c radionuclide angiography for control $(C)$, with atenolol $(A)$, and with atenolol and nifedipine

combined $(A+N)$. The mean (-) for each group is given at each assessment.

nifedipine $60 \mathrm{mg} /$ day was added to atenolol, though neither change was statistically significant (Fig. 4). The small rise in supine systolic blood pressure was also insignificant as was the small fall in erect systolic blood pressure. The diastolic pressures were not changed significantly in either position. The surface electrocardiogram showed no prolongation of the PR interval when nifedipine was added to atenolol. The reductions in systolic blood pressure and rate pressure product seen at peak exercise with atenolol (Fig. 5) were not enhanced by the addition of nifedipine nor was there sinus acceleration. Neither the ejection fraction nor the peak ejection rate (Fig. 6) was significantly modified by atenolol. With the combination of oral nifedipine and atenolol there was, however, a significant increase $(p<0.01)$ in the peak ejection rate but not in the ejection fraction.

\section{Discussion}

This study was designed to evaluate the haemodynamic and electrophysiological effects of nifedipine given intravenously and then orally to patients with normal left ventricular function who were receiving concurrent beta blocking doses of atenolol. A uniform and pronounced degree of beta blockade was confirmed in each patient before the administration of nifedipine.

The negative inotropic effect of intravenous nifedipine given in the presence of beta blockade was almost identical to that seen in a previous study in which sublingual nifedipine was given to patients who had received a single dose of atenolol. ${ }^{24}$ In our study the combination of oral nifedipine with atenolol did not change the ejection fraction as assessed by 
radionuclide angiography, nor was the rate pressure product further reduced from the changes induced by atenolol alone. The increase in peak ejection rate shown by radionuclide angiography is consistent with a vasodilator action of nifedipine, although there was a trivial rise in resting systolic blood pressure.

Nifedipine given alone produces a predominant reduction in afterload as systemic vascular resistance falls. ${ }^{32-34}$ The strong reflex sympathetic response that is elicited counteracts the potential negative inotropic action and is reflected as sinus acceleration. ${ }^{35}$ As a result left ventricular performance is unchanged or enhanced, and there may be increases in cardiac output and ejection fraction. ${ }^{2233^{-36}}$ Such improvement in left ventricular function may be evident in patients with diminished left ventricular contractility. 263738 Furthermore, the improvement may be significantly greater in patients with impaired left ventricular function compared with that in normal patients, ${ }^{39}$ an effect that may be maintained during exercise. ${ }^{26}$ Others, however, have shown that when left ventricular function is impaired nifedipine can produce a profound fall in systemic vascular resistance accompanied by a decrease in myocardial contractility and cardiac failure. ${ }^{40}$

The degree of beta blockade has not been evaluated in previous studies of the haemodynamic effects of combining nifedipine with beta blockers. Various beta blockers have been used and, furthermore, in all but one study ${ }^{25}$ nifedipine $10 \mathrm{mg}$ sublingually was used. Koch ${ }^{23}$ combined nifedipine with both the acute and chronic administration of metoprolol. The improvement in stroke volume and cardiac output following nifedipine given after a single dose of metoprolol was accompanied by a rise in catecholamines. When metoprolol had been given chronically nifedipine did not improve left ventricular performance although there was still a rise in catecholamines. The negative inotropic effect of nifedipine, seen experimentally but disguised by reflex autonomic changes when nifedipine is given alone, was shown by a study of nifedipine given in a single sublingual dose to patients receiving atenolol; there was no change in ejection fraction. ${ }^{24}$ In another study the negative inotropic effects of acebutolol on left ventricular performance were balanced by the vasodilator action of nifedipine, even in a subset of patients with borderline heart failure. ${ }^{26} \mathrm{~A}$ more recent study, in which nifedipine was given to patients with normal left ventricular function taking variable doses of propranolol, did not find a fall in $\mathrm{dP} / \mathrm{dt}$ but confirmed the improvement in left ventricular performance. ${ }^{22}$ The safety of the combination was, however, questioned by Monassier et al., ${ }^{25}$ who gave nifedipine in a higher dose (20 mg sublingually) to patients given acebutolol acutely. Compared with acebutolol alone there was a significantly greater degree of myocardial depression with the combination; all patients had normal left ventricular ejection fractions at rest. Despite these contradictory findings numerous studies have attested to the beneficial effects of combining beta blockers with calcium antagonists in the treatment of patients with angina. The occasional reports of the precipitation of severe heart failure with the combination ${ }^{15-17}$ have confirmed that a proper understanding of the interaction between nifedipine and calcium antagonists is required and have stressed the importance of taking the underlying ventricular function into consideration.

Nifedipine has been shown to lack appreciable electrophysiological action in man when used in doses sufficient to produce its antianginal effects. ${ }^{28} 29$ The only change observed after intravenous nifedipine given alone is a reflex mediated sinus acceleration. Experimental work has shown that if nifedipine and verapamil are given in equal doses they impair atrioventricular nodal function to the same extent. ${ }^{7}$ The vasoactive effects of nifedipine, however, necessary for its antianginal efficacy, are produced at much lower concentrations than those of verapamil, allowing nifedipine to be used in quantities that have no direct electrophysiological inhibition. The reflex mediated increase in sympathetic tone consequent on the vasoactive effects produces sinus acceleration; it also acts on the atrioventricular node, though junctional acceleration can be seen only when there is sinus node disease. ${ }^{41}$ There is no change in atrioventricular nodal conduction or refractoriness in the normal patient. In experimental studies using the denervated dog heart, however, it has been shown that nifedipine prolongs atrioventricular nodal conduction times and refractoriness at concentrations which have no effect when innervation is intact. ${ }^{30}$ Similarly, the sensitivity of atrioventricular conduction to verapamil can be increased profoundly by depletion of catecholamines. ${ }^{42}$ Our study indicated a depressant action of intravenous nifedipine on atrioventricular nodal function in patients who were adequately beta blocked. This influence was transient, however, and seen only when sensitive tests of atrioventricular nodal function were used: the absence of any change in resting atrioventricular nodal conduction time means that simple electrocardiographic scrutiny (for example, the PR interval) would not show these minimal changes. These changes are in clear contrast to the profound electrophysiological effects of two other calcium antagonists, verapamil and diltiazem, evident in all the tests of atrioventricular nodal function and seen when the drugs are given in the absence of beta blockade.

Our results suggest that the use of these drugs in 
combination is safe in patients with normal left ventricular function. The protocol specifically excluded patients with impaired left ventricular function, as assessed by contrast and radionuclide angiography, and we are at present exploring the safety of the combination when left ventricular function is impaired. Similarly, our electrophysiological results, though suggestive of increased sensitivity of atrioventricular nodal function to nifedipine in the presence of beta blockade, indicate that patients with normal atrioventricular nodal function will not be affected adversely by the combination.

Intravenous nifedipine was kindly supplied by Bayer (UK) Ltd.

\section{References}

1 Greenblatt DJ, Koch-Weser J. Adverse reactions to beta adrenergic receptor blocking drugs: a report from the Boston Collaborative Drug Surveillance Programme. Drugs 1974; 7: 118-29.

2 Braunwald E. Mechanism of action of calcium-channelblocking agents. $N$ Engl f Med 1982; 307: 1618-27.

3 Fleckenstein A, Tritthart H, Fleckenstein B, Herbst A, Grun G. Eine neue Gruppe kompetitiver zweiwertiges $\mathrm{Ca}^{++}$-Antagonisten (Iproveratril, D600, Prenylamin) mit starken Hemeffekten auf die elektromekanische Koppelung im Warmblüter-Myokard. Pfluegers Arch 1969; 307: R25.

4 Fleckenstein A. Specific pharmacology of calcium in the myocardium, cardiac pacemakers, and vascular smooth muscle. Annu Rev Pharmacol Toxicol 1977; 17: 149-66.

5 Kohlhardt M, Fleckenstein A. Inhibition of the slow inward current by nifedipine in mammalian ventricular myocardium. Naunyn Schmiedebergs Arch Pharmacol 1977; 298: 267-72.

6 Henry PD. Comparative pharmacology of calcium antagonists: nifedipine, verapamil and diltiazem. $A m \mathcal{F}$ Cardiol 1980; 46: 1047-58.

7 Taira N, Narimatsu A. Effects of nifedipine, a potent calcium-antagonistic coronary vasodilator, on atrioventricular conduction and blood flow in the isolated atrioventricular node preparation of the dog. Naunym Schmiedebergs Arch Pharmacol 1975; 290: 107-12.

8 Rashack M. Differences in the cardiac actions of the calcium antagonists verapamil and nifedipine. Arzneim Forsch 1976; 26: 1330-3.

9 Heupler FA Jr, Proudfit WL. Nifedipine therapy for refractory coronary arterial spasm. Am $\mathcal{F}$ Cardiol 1979; 44: 798-803.

10 Goldberg S, Reichek N, Wilson J, Hirshfeld JW Jr, Muller J, Kastor JA. Nifedipine in the treatment of Prinzmetal's (variant) angina. Am f Cardiol 1979; 44: 804-10.

11 Théroux P, Waters DD, Affaki GS, Crittin J, Bonan R, Mizgala HF. Provocative testing with ergonovine to evaluate the efficacy of treatment with calcium antagonists in variant angina. Circulation 1979; 60: 504-10.

12 Ekelund L-G, Orö L. Anti-anginal efficiency of nifedipine with and without a beta-blocker studied with exercise test. A double blind randomised subacute study. Clin Cardiol 1979; 2: 203-11.

13 Kenmure ACF, Scruton JH. A double-blind controlled trial of the anti-anginal efficacy of nifedipine compared with propranolol. Br $\mathcal{f}$ Clin Pract 1979; 33: 49-51.

14 Lynch P, Dargie H, Krikler S, Krikler D. Objective assessment of antianginal treatment: a double-blind comparison of propranolol, nifedipine and their combination. $\mathrm{Br}$ Med $\mathcal{F}$ 1980; 281: 184-7.

15 Anasstassiades CJ. Nifedipine and beta-blocker drugs. Br Med F 1980; 281: 1251-2.

16 Opie $\mathrm{LH}$, White DA. Adverse interaction between nifedipine and $\beta$-blockade. $\mathrm{Br}$ Med $\mathcal{F}$ 1980; 281: 1462.

17 Robson RH, Vishwanath MC. Nifedipine and betablockade as a cause of cardiac failure. $\mathrm{Br}$ Med $\mathcal{F}$ 1982; 284: 104.

18 Denis B, Pellet J, Machecourt J, Martin-Noel P. Vérapamil et bêta-bloquant: une association thérapeutique dangereuse. Nouv Presse Med 1977; 6: 2075.

19 Chew CYC, Hecht HS, Collett JT, McAllister RG, Singh BN. Influence of severity of ventricular dysfunction on hemodynamic responses to intravenously administered verapamil in ischemic heart disease. Am $\mathcal{F}$ Cardiol 1981; 47: 917-22.

20 Leon MB, Rosing DR, Bonow RO, Lipson LC, Epstein SE. Clinical efficacy of verapamil alone and combined with propranolol in treating patients with chronic stable angina pectoris. Am f Cardiol 1981; 48: 131-9.

21 Subramanian B, Bowles MJ, Davies AB, Raftery EB. Combined therapy with verapamil and propranolol in chronic stable angina. Am $\mathcal{F}$ Cardiol 1982; 49: 125-32.

22 Winniford MD, Markham RV Jr, Firth BG, Nicod P, Hillis LD. Hemodynamic and electrophysiologic effects of verapamil and nifedipine in patients on propranolol. Am $\mathcal{F}$ Cardiol 1982; 50: 704-10.

23 Koch G. Beta-receptor and calcium blockade in ischemic heart disease: effects on systemic and pulmonary hemodynamics and on plasma catecholamines at rest and during exercise. In: Puech P, Krebs R, eds. Fourth international Adalat symposium. New therapy of ischemic heart disease. Amsterdam, Oxford, Princeton: Excerpta Medica, 1980: 131-42.

24 Joshi PI, Dalal JJ, Ruttley MSJ, Sheridan DJ, Henderson $\mathrm{AH}$. Nifedipine and left ventricular function in beta-blocked patients. Br Heart $\mathcal{F}$ 1981; 45: 457-9.

25 Monassier JP, Coulbois PM, Doll JW, Weiss JB, Basch B, Monassier Ch. Effets hémodynamiques de l'association nifédipine-acébutolol. Arch Mal Coeur 1982; 75: $317-24$.

26 Pfisterer M, Müller-Brand J, Burkart F. Combined acebutolol/nifedipine therapy in patients with chronic coronary artery disease: additional improvement of ischemia-induced left ventricular dysfunction. $A m \mathcal{F}$ Cardiol 1982; 49: 1259-66.

27 Benaim ME. Asystole after verapamil [Letter]. $\mathrm{Br} \mathrm{Med} \mathcal{f}$ 1972; ii: $169-70$.

28 Rowland E, Evans T, Krikler D. Effect of nifedipine on atrioventricular conduction as compared with verapamil. Intracardiac electrophysiological study. Br Heart $\mathcal{f}$ 1979; 42: 124-7.

29 Padeletti L, Franchi F, Brat A, Dabizzi RP, Michelucci A. The cardiac electrophysiological effects of nifedipine. 
Int $\mathcal{f}$ Clin Pharmacol Biopharm 1979; 17: 290-3.

30 Taira N, Motomura S, Narimatsu A, lijima T. Experimental pharmacological investigations of effects of nifedipine on atrioventricular conduction in comparison with those of other coronary vasodilators. In: Lochner W, Braasch W, Kroneberg G, eds. Second international Adalat symposium. New therapy of ischemic heart disease. Berlin: Springer-Verlag, 1975: 40-8.

31 Sugrue DD, Kamal S, Deanfield JE, et al. Assessment of right ventricular function and anatomy using peripheral vein infusion of krypton $81 \mathrm{~m}$. $\mathrm{Br} \mathcal{F}$ Radiol 1983; 56: 657-63.

32 Lydtin $H$, Lohmöller G, Lohmöller $R$, Walter I. Hemodynamic studies on nifedipine in man. In: Lochner W, Braasch W, Kronenberg G, eds. Second international Adalat symposium. New therapy of ischemic heart disease. Berlin, Heidelberg, New York: Springer-Verlag, 1975: 97-106.

33 Van den Brand $M$, Remme WJ, Meester GT, Tiggelaar-de Widt J, de Ruiter R, Hugenholtz PG. Hemodynamic effect of nifedipine (Adalat $\left.{ }^{(}\right)$in patients catheterized for coronary artery disease. In: Lochner W, Braasch W, Kroneberg G, eds. Second international Adalat symposium. New therapy of ischemic heart disease. Berlin, Heidelberg, New York: Springer-Verlag, 1975: 142-52.

34 Olivari MT, Bartorelli C, Polese A, Fiorentini C, Moruzzi P, Guazzi MD. Treatment of hypertension with nifedipine, a calcium antagonist agent. Circulation 1979; 59: $1056-62$.

35 White SW, Porges WL, McRitchie RJ. Coronary haemodynamic effects of nifedipine (Bay a 1040) and glyceryl trinitrate in unanaesthetized dogs. Clin Exp Pharmacol Physiol 1974; 1: 77-86.

36 Johnson SM, Mauritson DR, Corbett J, et al. Effects of verapamil and nifedipine on left ventricular function at rest and during exercise in patients with Prinzmetal's variant angina pectoris. Am $\mathcal{F}$ Cardiol 1981; 47: 1289-94.

37 Klugmann S, Salvi A, Camerini F. Haemodynamic effects of nifedipine in heart failure. Br Heart $\mathcal{Y}$ 1980; 43: 440-6.

38 Matsumoto S, Ito T, Sada T, et al. Hemodynamic effects of nifedipine in congestive heart failure. Am $\mathcal{F}$ Cardiol 1980; 46: 476-80.

39 Ludbrook PA, Tiefenbrunn AJ, Sobel BE. Influence of nifedipine on left ventricular systolic and diastolic function. Relationships to manifestations of ischemia and congestive failure. Am $\mathcal{F}$ Med 1981; 71: 683-92.

40 Brooks N, Cattell M, Pidgeon J, Balcon R. Unpredictable response to nifedipine in severe cardiac failure. $\mathrm{Br}$ Med F 1980; 281 : 1324.

41 Krikler DM, Harris L, Rowland E. Calcium-channel blockers and beta blockers: advantages and disadvantages of combination therapy in chronic stable angina pectoris. Am Heart $\mathcal{F}$ 1982; 104: 702-8.

42 Urthaler F, James TN. Experimental studies on the pathogenesis of asystole after verapamil in the dog. $A m \mathcal{F}$ Cardiol 1979; 44: 651-6.

Requests for reprints to Dr E Rowland, Cardiovascular Unit, Hammersmith Hospital, London W12 0HS. 